\title{
LUDICIDADE NA EDUCAÇÃO INFANTIL: ASPECTOS HISTÓRICOS E PEDAGÓGICOS
}

\author{
Marlene Santana de Sene ${ }^{1}$ \\ Jucilene Campos de Almeida Silva ${ }^{2}$ \\ Denis de Moraes Dias dos Santos ${ }^{3}$ \\ Maria Marlene Pinheiro ${ }^{4}$
}

RESUMO: Os fatores sociais sempre interferiram na maneira de se compreender infância e, também, no modo de se tratar educação infantil. Atualmente não é diferente, com isso é necessário, implementar ações que busquem a melhor forma de se trabalhar educação infantil, evitando a mecanização das crianças. Desta forma, esse artigo trabalha com o papel da ludicidade na educação infantil, mostrando como se modificou a percepção de infância ao logo do tempo e como isso influenciou nas medidas educativas, resgatando os conceitos sobre ludicidade, trazendo um apanhando histórico sobre tal, e também pontuando sobre práticas educativas. A parti disso, percebemos como a introdução de práticas lúdicas permitem uma construção de dinâmica do conhecimento, fornecendo uma formação crítica e criativa.

Palavras-chave: Ludicidade. Educação. Infância. Criança. Práticas pedagógicas.

\section{INTRODUÇÃO}

O estilo de vida da sociedade atual está cada vez mais dinâmico, a crescente necessidade em realizar inúmeras tarefas em um período cada vez mais curto de tempo faz com que o cotidiano seja cada vez mais corrido, principalmente nos grandes centros. Essa estrutura, exige que as pessoas cumpram metas, gerando assim uma evidente mecanização das relações de sociais e de trabalho, somado a isso, temos a grande produção de informação, a cada instante mais e mais informações surge, o acesso a essa também está cada vez mais fácil e veloz.

\footnotetext{
${ }^{1}$ Graduada em Licenciatura em pedagogia pela universidade de Cuiabá e pós-graduada em Educação Infantil e Alfabetização pela Faculdade Invest de Ciências e Tecnolog E-mail: marlenesener4@hotmail.com.

${ }^{2}$ Graduada em licenciatura em Pedagogia com ênfase na Educação Infantil pela NEAD/UFMT.

${ }_{3}^{3}$ Graduada em pedagogia pela Faculdade Anhanguera e pós-graduada em Ludo pedagogia pela Facitec.

${ }_{4}$ Graduada em Pedagogia pela Unic Universidade de Cuiabá.
} 
Esses fatores, influenciam diretamente na educação infantil, pois, a falta de tempo acarreta numa diminuição das práticas interativas coma as crianças, e o acesso a toda essa informação pode tornar a criança um agente passivo do conhecimento. Dessa forma, atividades lúdicas se tornam uma ferramenta indispensável na reparação dessas falhas sociais.

Para se entender a importância da ludicidade na educação infantil, é necessário compreender algumas características intrínsecas das crianças, para posteriormente entender que seu mecanismo de aprendizagem é muito dependente das experiências sensórias. A percepção da singularidade da criança é algo que foi construído historicamente, e foi totalmente influenciada pelas relações sociais de cada época, atualmente não é diferente, nossa percepção de infância parte das nossas relações sociais, essa percepção e fundamental na construção de uma educação lúdica.

Somado a isso, temos as práticas pedagógicas adotadas para materializar a ideia de uma educação lúdica, uma boa atividade educativa é aquela que permite que professor e aluno sejam agentes ativos no processo do conhecimento. Para traçar um panorama da ludicidade nos dias atuais, é necessário antes de tudo conceituar o tema abordado e, também, fazer um apanhado histórico e evolutivo.

Dessa maneira, essa pesquisa tem por objetivo relatar sobre a ludicidade na educação infantil, abordando alguns conceitos e temas importantes para o assunto, buscando compreender qual a melhor forma de desperta o interesse da criança na escola e como o agente educador pode agir nesse processo.

\section{LUDICIDADE: CONCEITO HISTÓRICO}

A palavra ludicidade te origem da palavra ludusque do latim significa jogar. Hoje, inúmeros autores, abordam a ludicidade estes tratam predominantemente sobre o papel dessa na vida humana: no desenvolvimento humano, nos processos pedagógicos, na recreação e divertimento. Além dos estudos de cunho histórico.

Apesar de vários estudos sobre o tema ainda há uma discordância, até mesmo contradições, em relação ao conceito de ludicidade. Na maioria dos casos seu significado está fortemente atrelado ao conceito de jogar ou brincar. 
Luckesi (2006) a idéias desse autor sobre ludicidade se expande para além da ideia de atividade recreativa. A ideias de ludicidade está associada a experiência interna dos indivíduos. Aos olhos do autor esse é um fenômeno interno do sujeito.

Luckesi (2006) deixa sua ideia mais clara no trecho que diz:

Brincar, jogar, agir ludicamente, exige uma entrega total do ser humano, corpo e mente, ao mesmo tempo. A atividade lúdica não admite divisão; e, as próprias atividades lúdicas, por si mesmas, nos conduzem para esse estado de consciência. Se estivermos num salão de dança e estivermos verdadeiramente dançando, não haverá lugar para outra coisa a não ser para o prazer e a alegria do movimento ritmado, harmônico e gracioso do corpo. Contudo, se estivermos num salão de dança, fazendo de conta que estamos dançando, mas de fato, estamos observando, com o olhar crítico e julgativo, como os outros dançam, com certeza, não estaremos vivenciando ludicamente esse momento"

O lúdico, segundo Luckesi, propicia uma experiência plena para o sujeito.

No pensamento de Santana (20II), ludicidade está atrelado a idade, a etapas do desenvolvimento do indivíduo. Esta concepção atribui ao jogo elemento de desenvolvimento intelectual, físico e mental. Sendo uma ação com forte teor educacional.

Segundo Leal (20II), o lúdico originou - se do latim "ludus", que significa “jogo”. Entretanto, não se pode ficar preso ao significado etimológico da palavra, uma vez feito isso, o que é lúdico estaria apenas se referindo ao ato espontâneo de brincar. Para cada fase da vida humana, o lúdico adquiri valores e papéis específicos, que são de fundamentais para o desenvolvimento do ser humano, desta forma, na infância e adolescência o lúdico se manifesta sobretudo de forma pedagógica.

Vygotsky em suas teorias diz que o indivíduo se desenvolve a partir da relação que possui com o outro. Citando ainda o jogo como elemento importante para este desenvolvimento, pois estimula o desfio e estímulos para novas conquistas.

Huizinga (1990) em sua obra "Homo Ludens: o jogo como elemento cultural", 1938, tem como objetivo demonstrar a importância do jogo desde as remotas civilizações. Conceitua o jogo no que abrange tanto sua manifestação competitiva quanto sua manifestação voluntaria. O jogo no sentido de alegria e de fantasia da realidade. 
O autor, já citado acima, Huizinga (1990) emprega ao jogo um componente da essência humana, sendo algo maior que necessidade do corpo ou da mente. Uma ação não meramente fisiológica ou biológica, mas com real significado.

Para Winnicott (1975) o brincar é a base da vida cultural, está ligado intimamente com a subjetividade do sujeito. No pensamento do autor é no brincar que se pode ser criativo e utilizar a personalidade.

\section{Infância: Período de desenvolvimento}

Para entender a temática infância, é necessário ter em mente que essa representação sofreu inúmeras mudanças com o passar do tempo. Essas diferenças na determinação do conceito de infância, fez com que as crianças vivenciassem de diferentes formas essa fase, determinação esta que está diretamente ligado ao modo de como os adultos se relacionam com as crianças. Segundo Bernartt (2009) apud Kramer: "Crianças são sujeitos sociais e históricos, marcadas, portanto, pelas contradições das sociedades em que estão inseridas”. (BERNARTT, 2009).

Não se tem muitos relatos sobre a concepção de infância na idade antiga, já na idade média, as crianças eram inseridas muito cedo na dinâmica de trabalho, pois a sociedade não tinha noção dessa transição da infância para a fase adulta, sua concepção era apenas que as crianças eram adultos em "miniatura", esse fato, culminou num grande índice de mortalidade infantil. $O$ fato de não se ter uma noção de infância não significa que a sociedade medieval não manifestava apreço pelas crianças, mas sim, que os mesmos não entendiam a particularidade de ser criança, que devido isso, os enxergavam como adultos. (BERNARTT, 2009 apud ARIES, 198I).

Foi na idade moderna onde a preocupação com a infância começa a ganhar uma maior importância, o Renascimento e o uso da razão foram dois fatores importantes na mudança da concepção de infância, nesse período onde surge a ideia de que se investir nas crianças é investir no futuro. (NASCIMENTO; BRANCHER; OLIVEIRA; 2007). Com essa linha de raciocínio, a criança começa a ser enxergada como um ser social de papel intrínseco e importante na sociedade, a parti daí começa a se reconhecer a singularidade dessa fase, acarretando numa nova forma de se pensar os tratamentos desse grupo.(BERNARTT, 2009).

No Brasil, na época da escravidão, crianças filhas dos nobres recebiam tratamentos privilegiado e todo cuidado necessário, já os filhos de escravos eram submetidos as mesmas condições de vida do país, e também eram iniciadas no trabalho de maneira precoce. Com o 
aumento dos centros urbanos e a desigualdade cada vez mais acentuada, a questão do trabalho na infância voltou a ser um problema. Com isso, a escola e o agente educador desempenham um papel importante, pois devem tornar a escola mais atrativa do que a vida fora dela, desta forma, ensinar com de maneira lúdica se torna fundamental, visando prender cada vez as crianças ao mundo acadêmico. (NASCIMENTO; BRANCHER; OLIVEIRA; 2007)

Atualmente, a concepção social de infância, leva em conta as peculiaridades dessa fase, possibilitando um melhor entendimento sobre o desenvolvimento infantil, podendo assim, traçar as melhores maneiras de estimular o desenvolvimento intelectual das crianças. As bases científicas também constituem um papel essencial na construção de uma boa prática educacional infantil, entender como se dá a absorção de conhecimento nessa fase possibilita o uso de práticas mais eficazes.

\section{Práticas Pedagógicas}

Por via de regra, quando se discuti ludicidade na educação infantil, é fundamental falar sobre as práticas pedagógicas envolvidas nesse processo. Práticas pedagógicas é algo que não pode ser definido de maneira absoluta, mas de acordo com Verdum (2013) nas práticas pedagógicas "a construção do conhecimento é vista como um processo realizado por ambos os atores, professor e aluno, na direção de uma leitura crítica da realidade”. Desta forma, as práticas pedagógicas permitem uma aprendizagem que traz a educação como pratica social e conhecimento como uma produção histórica e social, nesse sentindo, o aluno se torna capaz de desenvolver tanto o lado intelectual quanto o crítico. (VERDUM, 2013).

Uma boa atividade educativa resulta numa via de mão de dupla, onde professor e aluno ensinam e apreendem, cada um com seu papel nessa dinâmica, construindo assim conhecimento de maneira dinâmica e enriquecedora. É importante pontuar, que apesar dessa dinâmica não admitir o professor como dono do conhecimento, é evidente sua importância como agente orientador e criador de interesse no educando, é nesse ponto que surge a importância do educador e de suas práticas lúdicas. (VERDUM, 2013).

Assim sendo, para despertar o pensamento crítico é necessário que seja empregada técnicas educacionais voltadas para a prática e construção de um ensino de maneira lúdica desde o início da jornada acadêmica da criança, para isso é imprescindível que se descontrua a visão de prática pedagógica como o ato de transmissão de conhecimento, onde uma parte é ativa e a outra é passiva e apenas recebe informações. Portanto, é válido ressaltar que essas práticas devem tratar conhecimento como algo que se constrói em conjunto, sendo os dois agentes ativos nesse processo. (VERDUM, 2013). 
Em vista disso, é notório a importância da efetivação desses conceitos e ideias apresentados, contudo, a ideia arcaica de ensino ainda tem algumas práticas enraizada no pensamento de alguns profissionais da educação, e essa mudança para, obrigatoriamente, pela formação dos profissionais, é preciso repensar a formação dos professores visando torna - los capazes de agir de maneira cada vez mais didática e lúdica. Nesse sentindo, Cavali (2006) descreve que:

O professor é entendido como um profissional que mobiliza e desenvolve saberes específicosa partir da própria prática. É um protagonista das práticas educativas e de sua formação profissional, capaz de construir a si próprio, de repensar criticamente sua prática, em consequência de suas experiências cotidianas no ensino". (CAVALI, 2006, p.378).

Então, se a formação dos professores for trabalhar nessa perspectiva, os mesmo se tornaram mais capazes de implantar práticas pedagógicas que estimulem a participação do aluno, de maneira que, ambos construam, em conjunto, o conhecimento necessário para uma boa formação acadêmica. (CAVALl, 2006).

\section{CONSIDERAÇÕES FINAIS}

No desenrolar -se desse artigo é possível compreender o papel da ludicidade da educação infantil, e como essa prática representa uma função importante no processo de aprendizagem, possibilitando o desenvolvimento integral (motoro, intelectual, social, físico etc.) da criança, haja vista, que nessa fase é necessário trabalhar, além da aplicação de conteúdo, as experiências reais, instigando a criança ao aprender e tornando -a ativa no processo de construção de conhecimento.

Portanto, é notório que para se alcançar esses objetivos é necessário ter bem claros conceitos que circundam esse cenário, entender todo o desenvolvimento histórico acerca do assunto, possibilita uma melhor compreensão de como adequar essas práticas para o momento atual. Compreender a infância também é essencial, uma vez que, é esse grupo o alvo principal dessas medidas, a parti disso, é possível traças as melhores práticas pedagógicas que resultaram na realização do objetivo de se trabalhar educação infantil de maneira lúdica.

Dessa maneira, nítido que aprender através do lúdico possibilita uma construção conjunta do conhecimento, possibilitando que o indivíduo se depara com dificuldades, podendo assim vencer suas próprias limitações. Nesse contexto, o papel 
do educador é indispensável, pois ele deve agir como mediador nesse processo, direcionando essas ações e dando apoio para os educandos.

As atividades lúdicas se encontram ameaçada, pois a educação mecanizada vem ganhando cada vez espaço, refletindo o atual modelo social que visa a maior otimização de tempo, entretanto, é papel do da educação recuperar o lúdico no ensino, formando pessoas com aptidões não só acadêmicas, mas também sociais e pessoais.

\section{BIBLIOGRÁFIA}

[I] BERNARTT, Roseane Mendes. IX CONGRESSO NACIONAL DE EDUCAÇÃO, 2009, Paraná. A INFÂNCIA A PARTIR DE UM OLHAR SÓCIOHISTÓRICO. Paraná: Pucpr, 2009. I2 p. Disponível em: $\langle$ http://www.pucpr.br/eventos/educere/educere2009/anais/pdf/260I_1685.pdf $\rangle$. Acesso em: 20 set. 2017.

[2] HUIZINGA, Johan. Homo Ludens. São Paulo: Perspectiva, I99o.

[3] LUCKESI, Cipriano. Estados de consciência e atividades lúdicas. In: PORTO, Bernadete. Educação e ludicidade. Ensaios 3. Salvador: UFBA.

[4] NASCIMENTO, Cláudia Terra do; BRANCHER, Vantoir Roberto; OLIVEIRA, Valeska Fortes de. A CONSTRUÇÃO SOCIAL DO CONCEITO DE INFÂNCIA: ALGUMAS INTERLOCUÇÕES HISTÓRICAS E SOCIOLÓGICAS. Revista Olhar do Professor, Ponta Grossa. 2007. Disponível em: <http://coral.ufsm.br/gepeis/wpcontent/uploads/20II/o8/infancias.pdf $>$. Acesso em: 20 set. 2017.

[5] MIRALHA, Jussara Oliveto. A PRÁTICA PEDAGÓGICA DE PROFESSORES DO ENSINO FUNDAMENTAL NA PERSPECTIVA DE UMA EDUCAÇÃO DE QUALIDADE PARA TODOS. 2008. 254 f. Dissertação (Mestrado) - Curso de Pósgraduação em Educação, Universidade Estadual Paulista, Presidente Prudente, 2008. Disponível em: 〈http://www2.fct.unesp.br/pos/educacao/teses/jussara_miralha.pdf〉. Acesso em: 20 set. 2017.

[6] CAVAlli, Suzana Cristina. AS PRÁTICAS PEDAGÓGICAS NA FORMAÇÃO DO PROFESSOR E NA CONSTRUÇÃO DE SUA IDENTIDADE. 20I6. I4 $\mathrm{f}$. Universidade Tuiuti do Paraná, Paraná, 2016. Disponível em: 〈http://www.pucpr.br/eventos/educere/educere2005/anaisEvento/documentos/com/ TCCIo66.pdf $>$. Acesso em: 20 set. 2017. 
[7] VERDUM, Priscila. Prática Pedagógica: o que é? O que envolve? Revista Educação Por Escrito, Rio Grande do Sul, v.4, n.I, p.I-I5, jul. 2013. Disponível em: <http://revistaseletronicas.pucrs.br/ojs/index.php/porescrito/article/viewFile/14376/9 703>. Acesso em: 20 set. 2017

[8] VYGOTSKY, L. S. A formação social da mente.São Paulo: Martins Fontes, 1984.

[9] WINNICOTT, D. W. Obrincar e a Realidade. Rio de Janeiro: Imago, 1975.

[ro] SCHOLZE, Darlene; BRANCHER, Vantoir Roberto; NASCIMENTO, Cláudia Terra do. O PAPEL DA LUDICIDADE NO PROCESSO DE APRENDIZAGEM INFANTIL. Revista da Faculdade de Educação, Santa Maria, v.8, n.7, p.69-82, dez. 2007. Disponível em: 〈http://www2.unemat.br/revistafaed/content/vol/vol_7_8/artigo_7_8/69_82.pdf〉. Acesso em: 20 set. 2017. 